THE KURUME MEDICAL JOURNAL

1974 Vol.21, No.4, P.101-109

\title{
INFLUENCE OF TETRODOTOXIN ON THE CONTRACTILE RESPONSE OF THE SMALL INTESTINE OF GUINEA-PIG PRODUCED BY PICRIC ACID AND ACETYLCHOLINE
}

\author{
KOICHIRO TAKASAKI AND HIROKO OGATA \\ Department of Pharmacology, Daiichi College of Pharmaceutical Sciences, \\ Fukuoka, Japan
}

(Received for publication October 28, 1974)

\begin{abstract}
Contraction of the small intestine of guinea-pig by PA $\left(2 \times 10^{-4} \mathrm{M}\right)$ was completely inhibited after administration of TTX $\left(10^{-7} \mathrm{M}\right)$, whereas higher concentration of MP or PP was required to produce a comparable inhibition of the effect of PA. After treatment with TTX or MP (both $5 \times 10^{-7} \mathrm{M}$ ), there was a slight enhancement of contraction by Ach $\left(10^{-7} \mathrm{M}\right)$, while the same concentration of PP failed to produce any appreciable effect for Achinduced contraction. Pretreatment of $10^{-4} \mathrm{M}$ of PP resulted a certain degree of inhibition of Ach-induced contraction, whereas no effect was exerted at all after comparable doses of TTX or MP. When the tissue was pretreated with TTX $\left(5 \times 10^{-7} \mathrm{M}\right)$, there were a suppression of the Ach liberation by PA $\left(2 \times 10^{-4} \mathrm{M}\right)$ and a slight reduction of the Ach uptake by tissue. These results seem to indicate that TTX, like MP, having affinity for the terminal cell of cholinergic nerve but being devoid of effect on the effector-cell, inhibits the release and uptake of Ach.
\end{abstract}

There are numerous reports about the effects of tetrodotoxin (TTX) on the responses to the stimulation of parasympathetic nerve and acetylcholine (Ach) on the smooth muscle (cf. 7) 16) 17).

However, the experimental findings for the action of TTX on the smooth muscle that have been reported are diverse and not necessarily in accord with various investigations. For example, even with only respect to effects on isolated guinea-pig small intestine, TTX was described to reduce contraction evoked by a transmural stimulation ${ }^{2)}$ and to produce no significant change in Ach liberation induced by intestinal extension ${ }^{4}$. On the other hand, some investigators reported that TTX has no effect upon the contraction caused by
$\mathrm{Ach}^{2)}$, and others described that TTX slightly suppresses or augments the Ach-induced contraction ${ }^{3)}{ }^{4)}{ }^{23}$ ). Nor is there a clear elucidation of the mechanism operating in these actions of TTX as yet.

Meanwhile, a study published demonstrates that morphine (MP) inhibits the liberation of Ach from the parasympathetic nerve-ending of isolated guineapig small intestine ${ }^{19) 20}$ and blocks the action of picric acid (PA) which gives rise to Ach release from the nerveending ${ }^{21)}{ }^{22)}$.

Our previous experiment revealed that TTX was capable of inhibiting significantly the PA-induced contraction of isolated guinea-pig small intestine at lower concentration than $\mathrm{MP}^{24}$. 
The present study was undertaken to investigate the effect of TTX at the parasympathetic nerve-ending as well as the underling mechanisms, in comparison with the effect of MP on isolated small intestine of guinea-pig.

\section{MATERIALS AND METHODS}

The observation of intestinal movement and tension:

A portion of isolated small intestine, approx. $1.5 \mathrm{~cm}$ in length, from a female guinea-pig weighing 250-320 g was suspended in a circulating organ bath containing Tyrode solution ( $30 \mathrm{ml}$ ) of Magnus apparatus. An intestinal segment was strained by about $500 \mathrm{mg}$ with a strain gauge (Nihon Kohden, SB-1T) and its movement and tension were traced, with a practically constant amplification (Nihon Kohden, RUP-10 or RUP-2-5 and AD-2-22), by means of an ink-writing recorder (Nihon Kohden, WI-130).

Observation was made in the first place of the effects on intestinal movement of PA or Ach applied with 10 min-interval. The intestine was washed twice or thrice with warm Tyrode solution during the interval. After obser-. vation of response to second dose of $\mathrm{PA}$ or Ach the intestine was re-washed and exposed 5 min later to TTX or other pretreatment drugs, followed, $5 \mathrm{~min}$ later, by application of $\mathrm{PA}$ or Ach in the same dose as before in order to examine the response of the pretreated tissue.

All drugs were made up in Tyrode solution, and their doses were determined as final molar concentrations in the organ bath. The drug solutions were added to the bath in a volume of $0.3 \mathrm{ml}$ in all instances, unless otherwise specified, after a comparable volume of the medium of the bath had been removed.
The measurement of acetylcholine:

A total length of small intestine isolated from a guinea-pig was cut into three equal parts each of which was further divided into three equal portions. The resulted nine segments of entire small intestine were divided into three groups so that all groups might contain segments from the upper through lower portions evenly. Segments in these groups were then placed respectively in three baths attached to the Magnus apparatus, and, 5 min later, Tyrode solution was added to the baths of group 1 and 2, and also TTX or MP (both $5 \times$ $10^{-7} \mathrm{M}$ ) to the bath of group 3. After 10 min the group 1 bath received only Tyrode solution to serve as the control, while group 2 and 3 baths were given PA $\left(2 \times 10^{-4} \mathrm{M}\right)$ or Ach $\left(10^{-4} \mathrm{M}\right)$ respectively. At 10 min after this treatment, tissue was removed from each bath and homogenized. The resultant tissue homogenate and the medium of the bath wer eassayed for Ach in accordance with the procedure of Hestrin ${ }^{5)}$, adopting partly the method of Miyazaki et al. ${ }^{14}$ as well.

Comparison was made as to intestinal tissue Ach and bath-medium Ach levels between each drug treated material and the untreated control. The changes were calculated as per cent of the control level and mean per cent changes obtained for respective drug treated groups. Separately, changes noted in the PA or Ach treated groups pretreated with TTX or MP were also assessed in comparison with the unpretreated groups receiving $\mathrm{PA}$ or Ach alone. Average per cent changes obtained similarly for respective groups.

Following drugs were used in this experiment ; picric acid (2,4,6-trinitrophenol, Ishizu) (PA), acetylcholine (acetylcholine chloride, Daiichi) (Ach), papaverine (papaverine hydrochloride, Dainippon) (PP), tetrodotoxin (Sigma) 
(TTX), morphine (morphine hydrochloride, Sankyo) (MP).

\section{RESULTS}

1. Changes in contractile response following repeated doses of picric acid or acetylcholine:

$\mathrm{PA}$ and Ach caused the most adequate contraction of the intestine when applied in a dose of $2 \times 10^{-4} \mathrm{M}$ and $10^{-7} \mathrm{M}$ respectively. The drugs were used at these dose levels throughout the following experiments.

As can be seen from Table 1, the contraction of the intestine increased approx. $59 \%$ on the average after the second dose of PA $\left(2 \times 10^{-4} \mathrm{M}\right)$ with 10 min-interval, compared with that noted after the first dose of this drug.

Similarly, there was some $44 \%$ increase in the case of Ach. In responses to the third dose of PA and Ach, however, the contractions increased and decreased only less than $5 \%$ in comparison with the level after the second dose of the drug's. Intestine showed an average diminution of contraction by about 30 $\%$ with the fourth dose of PA below the

\section{TABLE 1}

Changes of contractile response to repeated administrations of picric acid and acetylcholine.

\begin{tabular}{|c|c|c|c|c|}
\hline $\begin{array}{l}\begin{array}{r}\text { Number of } \\
\text { administ- } \\
\text { rations }\end{array} \\
\text { Drugs } \\
\text { and doses }\end{array}$ & $\begin{array}{c}1 \\
\text { Control }\end{array}$ & $\begin{array}{l}2 \\
\circ\end{array}$ & 3 & 4 \\
\hline $\begin{array}{l}\text { Picric acid } \\
2 \times 10^{-4} \mathrm{M} \\
(10)\end{array}$ & & $\begin{array}{c}+58.6^{*} \\
\pm \\
2.2\end{array}$ & $\begin{array}{c}+63.6 \\
\pm \\
1.9\end{array}$ & $\begin{array}{c}+34.2 \\
\pm \\
2.3\end{array}$ \\
\hline $\begin{array}{l}\text { Acetylcholine } \\
10^{-7} \mathrm{M} \\
\text { (10) }\end{array}$ & . & $\begin{array}{c}+44.0 \\
\pm \\
2.6\end{array}$ & $\begin{array}{c}+40.9 \\
\pm \\
2.9\end{array}$ & $\begin{array}{c}+35.8 \\
\pm \\
2.9\end{array}$ \\
\hline
\end{tabular}

* Mean per cent change from control (mean \pm s.e.). Numerals in ( ) indicate the number of experiments. level after the preceding dose, whereas there was only about $5 \%$ decrease in the case of Ach.

In view of these findings, the degree of contraction produced after the second dose of PA or Ach was described to be taken as the control level in the following experiments carried out to assess the effect of pretreatment with TTX or other drugs.

\section{Changes in intestinal movement and} tension after tetrodotoxin, morphine and papaverine:

Treatment with TTX or MP $\left(10^{-8} \mathrm{M}\right.$ $10^{-7} \mathrm{M}$ ) caused a slight relaxation of the intestine. A slight suppression of intestinal movement with further significant relaxation occurred after treatment with TTX or MP $\left(10^{-6} \mathrm{M}-10^{-4} \mathrm{M}\right)$. With high doses of TTX or MP, a transient cessation of movement or a marked relaxation occurred immediately after the treatment in some cases, although these effects disappeared within a few min and normal motility redeveloped. Administration of PP $\left(10^{-8} \mathrm{M}-10^{-6} \mathrm{M}\right)$ caused virtually no influence on the intestinal movement whilst depression of movement and relaxation were evident after addition of $10^{-5} \mathrm{M}$ or higher doses to the bath. Sustained cessation of movement and relaxation were observed after further increased doses.

\section{Influence of tetrodotoxin, morphine} and papaverine on the contractile response to picric acid:

Contraction of the intestine produced by PA $\left(2 \times 10^{-4} \mathrm{M}\right)$ was scarcely affected by pretreatment with TTX at concentration not higher than $10^{-8} \mathrm{M}$, whereas it was inhibited by higher doses of TTX, the inhibition being complete by TTX $\left(10^{-7} \mathrm{M}\right)$. Complete suppression of the effect of PA was also accomplished by 
pretreatment with $5 \times 10^{-7} \mathrm{M}$ or higher concentration of MP, while PP was required at concentration as higher as $5 \times 10^{-5} \mathrm{M}$ to obtain such a complete inhibition.

The inhibitory effects of TTX and other drugs could be reversed promptly after washing the intestine with sufficient amounts of Tyrode solution.

Fig. 1 shows some representative results and Fig. 2 illustrates the mean dose-effect curves obtained in these experiments.

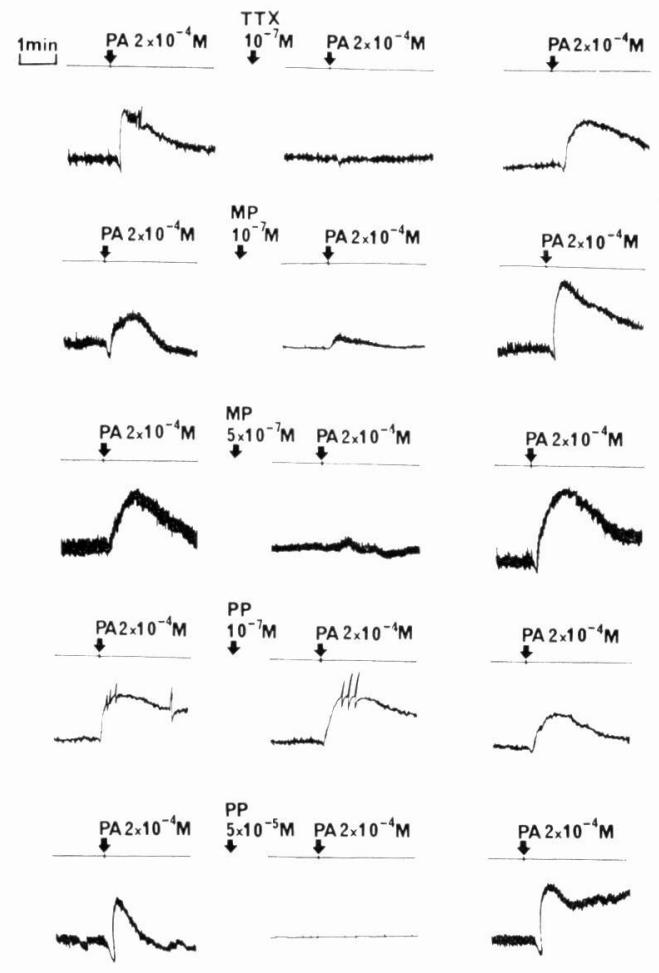

Fig. 1 Inhibitory effects of tetrodotoxin, morphine and papaverine on the contractile response to picric acid.

4. Influence of tetrodotoxin, mor phine and papaverine on the contractile response to acetylcholine:

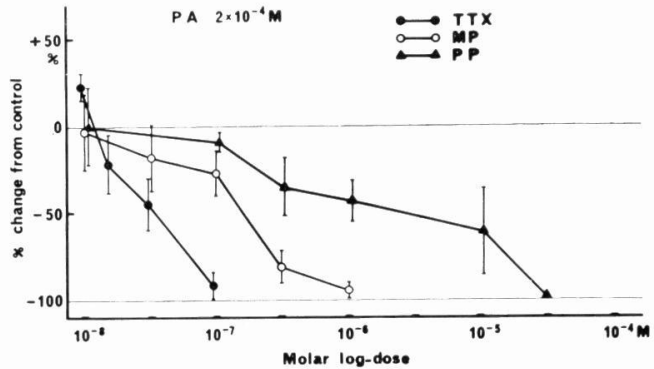

Fig. 2 Dose-effect curves of tetrodotoxin, morphine and papaverine on the contractile response to picric acid.

Each value was obtained from $3-8$ experiments, except that from 2 experiments in the case of papaverine $\left(5 \times 10^{-5} \mathrm{M}\right)$.

Bars show a standard error.

A significant increase of Ach $\left(10^{-7}\right)$ induced contraction by an average of $40 \%$ was brought about in the intestine pretreated with TTX $\left(5 \times 10^{-7} \mathrm{M}\right)$. Intestine failed to exhibit such conspicuous augmentation of the effect of Ach when pretreated with MP $\left(5 \times 10^{-7} \mathrm{M}\right)$ as that observed after TTX. Although Ach-induced contraction was scarcely affected by pretreatment with TTX or MP (both $10^{-4} \mathrm{M}$ ), suppression of the effect of Ach was evident after treatment with MP $\left(10^{-3} \mathrm{M}\right)$. PP at concentration not higher than $10^{-5} \mathrm{M}$ exerted no appreciable influence on the effect of Ach, whereas at $10^{-4} \mathrm{M}-10^{-3} \mathrm{M}$ it caused a pronounced inhibition. These enhancing effects of TTX or other drug pretreatment tended to be sustained even after washing with Tyrode solution in some cases, while washing facilitated less efficiently the recovery of inhibitory effect.

Fig. 3 shows some representative data and Fig. 4 illustrates the mean doseeffect curves observed in these experiments. 


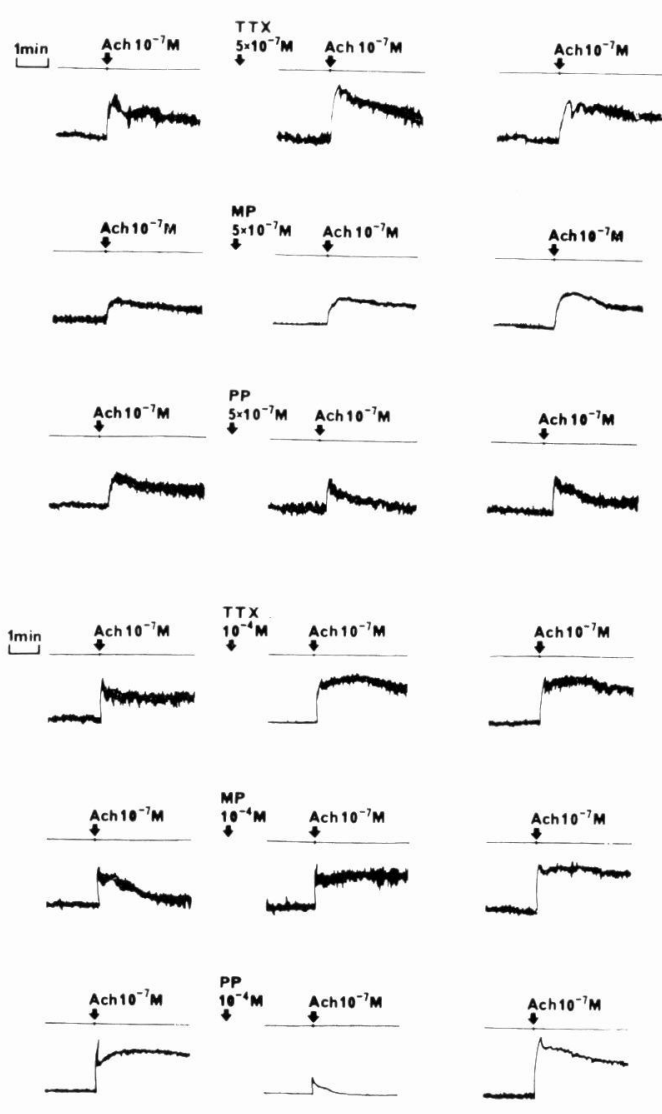

Fig. 3 Enhancement and inhibition of the contractile response to acetylcholine after treatment of tetrodotoxin, morphine or papaverine.

5. Influence of tetrodotoxin and morphine on the changes of acetylcholine contents in intestinal tissue and the organ bath after treat ment with picric acid or acetylcholine:

PA added at a dose of $2 \times 10^{-4} \mathrm{M}$ caused $17-23 \%$ diminution of Ach content in the intestinal tissue and 20-53\% elevation of Ach in the organ bath-medium

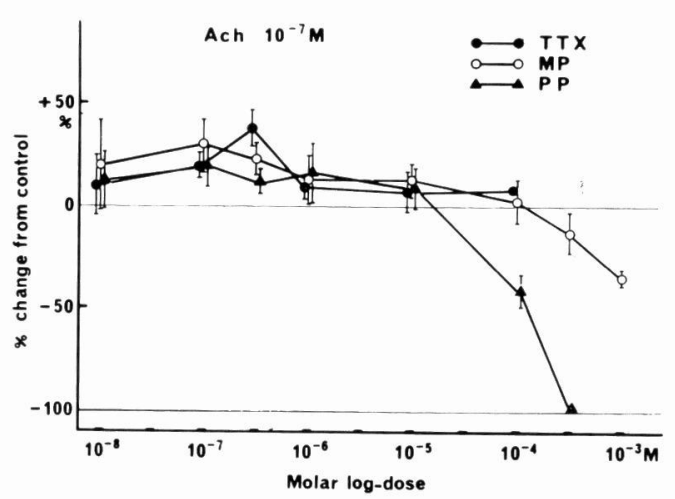

Fig. 4 Dose-effect curves of tetrodotoxin, morphine and papaverine on the contractile response to acetylcholine.

Each value was obtained from 3-19 experiments. Bars show a standard error.

on the average. Such alteration of tissue and medium Ach content by PA $\left(2 \times 10^{-4} \mathrm{M}\right)$ was, nevertheless, found to be almost completely prevented by pretreatment with TTX or MP (broth $5 \times$ $\left.10^{-7} \mathrm{M}\right)$. This effect of TTX against PA was more slightly conspicuous than observed with MP.

Meanwhile, the tissue and medium Ach levels rose 28 and $36 \%$ respectively after administration of Ach $\left(10^{-4} \mathrm{M}\right)$. When pretreated with TTX $\left(5 \times 10^{-7} \mathrm{M}\right)$, the intestine displayed a diminished increase of $21 \%$ in the tissue Ach content and an enhanced increase of medium Ach by about $45 \%$. The influence of MP $\left(5 \times 10^{-7} \mathrm{M}\right)$ for increase of Ach levels in the tissue and medium after treatment of Ach $\left(10^{-4} \mathrm{M}\right)$ was found to be the same tendency to the effect of TTX but it was not significantly observed.

These experimental results were summarized in Fig. 5. 


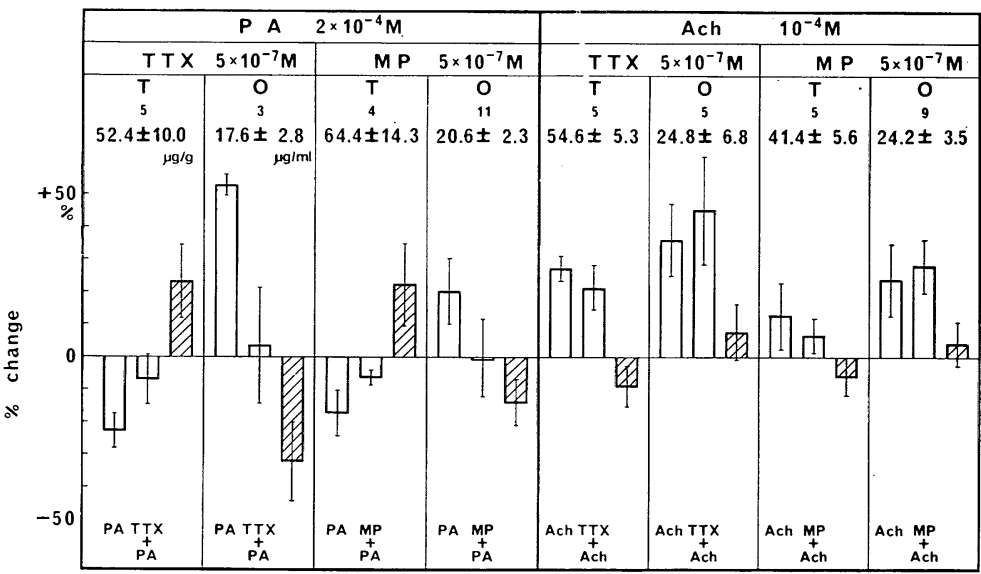

Fig. 5 Mean per cent changes of acetylcholine contents in the tissue of intestine and organ bath after picric acid or acetylcholine incubations, and influences of tetrodotoxin and morphine pretreatments.

$\mathrm{T}$ : tissue, $\mathrm{O}$ : organ bath. Numerals under $\mathrm{T}$ and $\mathrm{O}$ indicate the number of experiment and mean acetylcholine content in control $(\mu \mathrm{g} / \mathrm{g}$ and $\mu \mathrm{g} / \mathrm{mi})$. IIIIII : mean per cent changes of acetylcholine content in the experiments of tetrodotoxin or morphine pretreatment from that experiments of only administered picric acid or acetylcholine.

\section{DISCUSSION}

Gershon ${ }^{2)}$, having noted blockade by TTX $\left(10^{-7} \mathrm{~g} / \mathrm{ml}\right)$ of contractions of guinea-pig ileum and rabbit jejunum produced by transmular or perivascular stimulations, and of guinea-pig and mouse stomach invoked by vagus stimulation, concluded that TTX had the effect of blocking the liberation of Ach which is known to take part in the conduction of nerve impulse. This suggests that TTX may act upon the parasympathetic nerve terminal cell.

PA was described by Takagi et al. ${ }^{21}$ ) 22), on the other hand, to be capable of causing liberation of Ach from the guinea-pig ileum to give rise consequently to its contraction.

The finding noted in the present investigation that the effect of $\mathrm{PA}$ was inhibited by low concentration of TTX, as well as the results of Ach assays, clearly demonstrates the ability of TTX to inhibit Ach release from the terminal cell by PA. This effect of TTX seems to be more conspicuous than of MP which is believed to block the release of Ach by $\mathrm{PA}^{21}{ }^{22}$. While there are investigators who are inclined to be negative about the effect of TTX on the receptor site, claiming that TTX did not affect the Ach-induced smooth muscle contraction at all ${ }^{2)}$, reports of slight, yet not clear, inhibition of the Ach effect on ileum ${ }^{3)}{ }^{4)}$ and those describing that TTX has no effect on or slightly augments the Ach effect ${ }^{23}$ ) are existent. There are also reports of absence of any significant effect or of some facilitating effect of TTX against Ach-induced contraction of other smooth muscle 2) 4) 18). Thus the findings heretofore reported are diverse and not 
well in accord. These findings, which cannot be integrated because of different experimental conditions such as the organs and concentrations of Ach and TTX employed, may hardly be construed as clearly elucidating the effect of TTX and the underlying mechanism.

In the study herein described, the Ach-induced contraction of isolated small intestine was noted to be little affected by low concentration of TTX but slightly enhanced by certain doses of TTX at that time the effect of PA was markedly inhibited. It is suggested by this finding that TTX may possibly

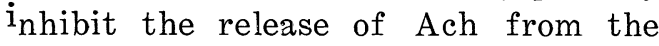
terminal cell, and at the same time block the Ach uptake by the terminal cell as well.

In the present study, evidence has been obtained in support of this hypothesis; Ach assays revealed significant diminution of Ach uptake by the terminal cell after addition of TTX to the bath. It follows that increased amounts of Ach at the receptor site and excitatory response of the effector organ are probably the consequence of the saidevents.

It has long been believed that TTX exerts a modest PP-like action on the smooth muscle itself ${ }^{3)}{ }^{8)}{ }^{13}$ ). In the present investigation, however, it was not until almost complete suppression by $\mathrm{PP}$ of intestinal tension with a consequent profound relaxation that the effects of PA or Ach were inhibited. With TTX, in contrast, slight inhibition of intestinal movement occurred even after a considerably high dose which nevertheless did not interfere with the action of Ach at all. These seem to indicate that the diminution of $\mathrm{PA}$ or Ach actions is not likely to be attributable immediately to the muscle-relaxant effect of TTX.
Moreover, there exists a. report of experiments demonstrating that TTX inhibits the effect of cholinesterase $(\mathrm{ChE})^{11)}$, where the doses of TTX employed therein exceeded those at which, in the present study, TTX produced enhancement of the Ach effect. In fact, the effect of Ach failed to be enhanced progressively despite increase in the dose of TTX, and there are investigators who are reluctant to admit the antiChE action of TTX ${ }^{16)}$. It appears accordingly that the enhancement of Ach action by TTX has no relation to its anti-ChE effect.

In addition, TTX has been described to affect slightly and rather inconspicuously the response to $\mathrm{CA}$, and that TTX is also said to inhibit the response to adrenergic nerve stimulation 1) 4) 6) 10) 18) 25). Our previous study also suggested the ability of TTX to act upon the adrenergic nerve-ending whereby the effect of CA was slightly augmented or conversely suppressed ${ }^{24}$. Inasmuch as the effect of Ach was shown in the present study to be enhanced by comparable concentration of TTX, the action of TTX on the adrenergic nerve might have a very little bearing upon its effects on Ach actions, though it is unlikely to constitute the primary cause of the enhancement or inhibition of Ach actions.

Reports have appeared in succession recently, describing that the mechanism of action of TTX on the nerve cell membrane consists in its ability to suppress selectively the $\mathrm{Na}^{+}$flux via the cell membrane ${ }^{12)}{ }^{15)} 26$ ). It is probable from this as well that TTX acts on the cell membrane of parasympathetic nerve ter minal to reduce the $\mathrm{Na}^{+}$permeation, thereby causing a suppression of PAinduced Ach release from or Ach uptake by the nerve-ending. 


\section{REFERENCES}

1) BELL, C.: Differential effects of tetrodotoxin on sympathomimetic action of nicotine and tyramine. Br. J. Pharmacol. Chemother., 32, 96-103, 1968.

2 ) Gershon, M. D. : Effects of tetrodotoxin on innervated smooth muscle preparations. Ibid., 29, 259-279, 1967.

3 ) Hamada, J.: The effect of tetrodotoxin crystals on the smooth muscle. I. The effect of tetrodotoxin in the isolated intestine. Annual Report of the Institute of Food Microbiology. Chiba University., 10, 73-77, 1957 (in Japanese).

4) Hamada, J. : The effect of tetrodotoxin crystals on the smooth muscle. II. The effect of tetrodotoxin and ganglionic active drugs in the isolated intestine and bronchial muscle. The Journal of Chiba Medical Society., 36, 1358-1368, 1960 (in Japanese).

5 ) HESTRIN, S.: The reaction of acetylcholine and other carboxylic acid derivatives with hydroxylamine, and its analytical application. J. Biol. Chemist., 180, 249-261, 1949.

6) Ishihara, F.: Über die Physiologischen Wirkungen des Fugutoxins. Mittelungen aus der Medizinischen Fakultät der Kaiserlichen Japanischen Univasität zu Tokyo., 20, 375-426, 1918.

7 ) KAO, C. Y.: Tetrodotoxin, paxitoxin and their significance in the study of excitation phenomena. Pharmacol. Rev., 13, 997 $-1049,1966$.

8 ) KaWAKAmi, K.: Pharmacological studies of the Fugu toxin. Igaku Kenkyu (Acta Medica), 22, 1273-1282, 1948 (in Japanese).

9 ) Kimura, S.: Zur Kenntnis der Wirkung des Tetrodongiftes. Tohoku J. Exp. Med., 9, 41-75, 1927.

10) Krauss, K.R., Carpenter, D.O. and Kopin, I. J.: Acetylcholine-induced release of norepinephrine in the presence of tetrodotoxin. J. Pharmacol. exp. Ther., 173, 416-421, 1970.

11) Kuriaki, K. and Nagano, H. : Susceptibility of certain enzymes of the central nervous system to tetrodotoxin. $\mathrm{Br}$. J. Pharmacol. Chemother., 12, 393-396, 1957.

12) Kuriyama, H., Osa, T. and Toida, N.: Effect of tetrodotoxin on smooth muscle cells of the guinea-pig taenia coli. Ibid, 27, 366-376, 1966.

13) Li Psius, M.R., Siegman, M.J. and Kao, C. $Y$.: Direct relaxant actions of procaine and tetrodotoxin on vascular smooth muscle. J. Pharmacol. exp. Ther., 164, 60-74, 1968.

14) Miyazaki, E., Ōhara, H., Kanno, A., MaRUYAMA, S. and $\bar{O} E, M$.: A new chemical quantitative measurement of acetylcholine and its biological application. Journal of Sapporo Medical College., 2, 7-12, 1951 (in Japanese).

15) Narahashi, T., Moore, J.W. and Scott, W.R.: Tetrodotoxin blockage of sodium conductance increase in lobster giant axons. J. General Physiol., 47, 965-973, 1964.

16) Ogura, Y.: Some recent knowledges on the Fugutoxin (tetrodotoxin). Seitai no Kagaku., 9, 281-287, 1958 (in Japanese).

17) Ogura, Y.: The progress in neurotoxin research on tetrodotoxin, trichatoxin, saxitoxin and cignatoxin. Igaku no Ayumi., 68, 243-252, 1969 (in Japanese).

18) Ozawa, H. and Sugawara, K. : Sites of action of crystalline tetrodotoxin on sympathetic nervous system. Japan. J. Pharmacol., 17, 287-297, 1967.

19) Schaumann, W. : The paralysing action of morphine on the guinea-pig ileum. Br. J. Pharmacol. Chemother., 10, 456-461, 1955.

20) Schaumann, W.: Inhibition by morphine of the release of acetylcholine from the intestine of the guinea-pig. Ibid., 12, 115-118, 1957.

21) TAKagi, K. and TAKayanagi, I. : Liberation of acetylcholine from the small intestines of guinea-pigs and cats after treatment with picric acid. Nature Lond., 193, 589590, 1962.

22) TAKAgI, K. and TAKAyanagi, I. : Effects of aromatic nitrocompounds and phenol derivatives on the cholinergic nerve ending of smooth muscle and skeletal muscle. Arch. int. Pharmacodyn. Thér., 155, 373$380,1965$.

23) TAkagi, K., TAkAyanagi, I. and TAgA, F. : Partial agonist and acetylcholine liberation. Br. J. Pharmacol. Chemother., 10, 57-63, 1970.

24) Takasaki, K., URabe, M. and Hiramine, Y. 
: Influence of tetrodotoxin on the actions of adrenergic and cholinergic drugs. Japan. J. Pharmacol., 23, Suppl. 20, 1973. 25) Tsukada, O. : Effect of tetrodotoxin crystals on the circulatory reflex and experimental arrythmia. The Journal of Chiba
Medical Society., 36, 1369-1379, 1960 (in Japanese).

26) Yanaga, T. and Holland, W. C.: Effect of tetrodotoxin on transmembrane potential of atrial muscle. J. Pharmacol. exp. Ther., 171, 20-25, 1970. 